\title{
A study of melamine-based mobility control of condensed water during steam flooding process
}

\author{
Xian Zhang ${ }^{1} \mathbb{0} \cdot$ Qingwang Liu ${ }^{1} \cdot$ Zhenzhong Fan $^{1} \cdot$ Hongchang Che ${ }^{2}$
}

Received: 11 January 2018 / Accepted: 4 July 2018 / Published online: 21 July 2018

(c) The Author(s) 2018

\begin{abstract}
The purpose of the research is to propose a novel method of mobility control of condensed water by melamine during steam flooding process. Melamine is working as water permeability modifier in a non-foaming manner to control mobility of condensed water, supported by the theoretic analysis. Wettability alternatation, water residual resistance factor, and oil displacement efficiecy by melamine addition were investigated in the experiments. The contact angle was decreased by $3.6^{\circ}$ at $200{ }^{\circ} \mathrm{C}$ indicating that the core tends to be more water wet upon addition of melamine. Water residual resistance factor, approximately representing water/oil mobility ratio, increased in response to the temperature elevation and increased pore volume during melamine injection. Water residual resistance factor reached close to 1 after subsequent hot water flood, which indicated that the reduced water permeability by melamine precipitation could be restored. The oil recovery by saturated melamine injection was increasd by $11.7 \%$ when temperature dropped from 200 to $160{ }^{\circ} \mathrm{C}$, in comparison with pure water flooding under the same condition. The results verify the feasibility of melamine to enhance oil recovery by controlling mobility of condensed water in a steam flooding process.
\end{abstract}

Keywords Heavy oil $\cdot$ Melamine $\cdot$ Thermal recovery $\cdot$ Mobility control $\cdot$ Laboratory

\section{Introduction}

The most frequently applied EOR method for producing heavy oil is steam flooding (Cai et al. 2013). Steam contains a large amount of heat to reduce the viscosity of heavy oil. The flooding efficiency was increased by mobility control using foam to divert steam into high oil saturated zones (Stoll et al. 1993). In general, there are four ways to control mobility during water or steam flooding process, namely by reducing oil viscosity and relative water permeability, or by increasing water viscosity and relative oil permeability. In a steam flooding reservoir, oil viscosity is dramatically reduced due to heat carried by steam transferring into the reservoir. Relative water permeability and water viscosity are often modified by addition of foaming additives.

Xian Zhang

zhangxianer@163.com

1 Petroleum Engineering Institute of Northeast Petroleum University, Daqing 163318, Heilongjiang, China

2 PetroChina Middle East, Beijing 100124, China
Numerous laboratory studies on the applicability of mobility control using foaming additives have been reported (Li et al. 2010, 2017; Nonnekes et al. 2015; Qian et al. 2016; Saleh et al. 2017). In steam flooding process, high-temperature-resistant surfactants are usually introduced for improving oil displacement efficiency. When these surfactants are foamed in situ, they partially seal the highly permeable reservoir zones and possess the ability to increase the viscosity of steam or water thus to enhance oil recovery. Foam flooding with steam injection also has some defects, one of which is the instability of the foam.

In steam flooding reservoirs, steam has experienced heat losses and condensed to water near displacement front where characteristics of hot water flood is exhibited $\mathrm{CHu}$ 2011). Mobility of condensed water has a great impact on the sweeping efficiency of steam and oil recovery can be increased by controlling it. From perspective of reducing water permeability, mobility control can be achieved by applying some kind of additive to plug off part of water flow paths. The additive shall be dissolved in hot water and steam while being injected along with them. They will be gradually precipitating from the saturated solution when temperature drops due to heat losses and energy consumption. In porous 
media, fractional flow of oil and water occurs within their own flow matrix without interfering each other. Water-wet additives preferentially occupy water flow matrix and effectively reduce relative water permeability without affecting the flow of oil. As a result, mobility control of condensed water is achieved and oil recovery is thus enhanced. With heat expansion along with continuous steam (or hot water) injection, precipitated substance is dissolved by the subsequent steam (hot water) and conveyed further to a zone where temperature is low enough for them to precipitate again. This process repeats itself until the additives break through to producer to be recovered to surface. When the injected additives are recovered, water permeability is reinstated. In other words, the reduction of relative water permeability is a temporary and reversible process, which causes no damage to reservoirs.

Little attention has been paid to reducing relative water permeability in a non-foaming manner in the previous studies of steam flooding. This paper is an attempt for mobility control using a non-foaming additive called melamine (MA) in the process of thermal recovery, which may provide EOR techniques with a different perspective.

\section{Theoretical fundamentals}

During steam flooding, there is a transition zone between the steam (hot zone) and the oil (cold zone) where the steam condenses to hot water. The transition zone can be regarded as the displacement front of the steam in terms of temperature profile. Ahead of the transition zone is the steam with high temperature while the cold oil with connate water is present behind it. The transition zone is advancing with continuous steam injection to drive the oil forward and our focus is to control it by application of the additive. According to fractional flow theory, either oil or water flows on its own path and does not influence each other. In water-wet rocks, water flows near the rock surface while oil flows through the center of the porous media. The additive is transported to transition zone and precipitates due to the sudden temperature drop. If the additive is hydrophilic it will occupy the water flow paths to reduce the water permeability without impact on the oil permeability, resulting in reduction in water/oil mobility ratio.

Based on Buckley and Leverett (1942), velocity of displacement front can be expressed as:

$\frac{\mathrm{d} x_{\mathrm{f}}}{\mathrm{d} t}=\frac{q_{\mathrm{t}}}{A \varphi}\left(\frac{f_{\mathrm{wf}}}{S_{\mathrm{wf}}-S_{\mathrm{wi}}}\right)$,

where $A$ is cross-sectional area, $\varphi$ is porosity, $x_{\mathrm{f}}$ denotes the location of front, $f_{\mathrm{wf}}$ is fractional flow to water at front, $S$ represents water saturation and subscripts $\{$ wi,wf $\}$ refer to connate water and water at front.

The oil recovery when breakthrough is expressed as:

$E_{\mathrm{R}}=\frac{\bar{S}_{\mathrm{W}}-S_{\mathrm{Wi}}}{1-S_{\mathrm{Wi}}}$,

where $E_{\mathrm{R}}$ denotes oil recovery and $\bar{S}_{\mathrm{W}}$ is average water saturation.

Fractional flow $f_{w}$ is the function of temperature $T$ and water saturation $S_{\mathrm{w}}$

$f_{\mathrm{W}}\left(S_{\mathrm{W}}, T\right)=\frac{1}{1+\frac{K_{\mathrm{ro}}}{K_{\mathrm{rW}}} \frac{\mu_{\mathrm{W}}}{\mu_{\mathrm{o}}}}$.

Because temperature $T_{1}$ ahead of front is higher than temperature $T_{0}$ behind front, fractional flow at $T_{1}$ and $T_{0}$ obeys the following relationship:

$f_{\mathrm{W}}\left(S_{\mathrm{W}}, T_{0}\right)=f_{\mathrm{W}}{ }^{(0)}\left(S_{\mathrm{W}}\right)>f_{\mathrm{W}}{ }^{(1)}\left(S_{\mathrm{W}}\right)=f_{\mathrm{W}}\left(S_{\mathrm{W}}, T_{1}\right)$.

The average water saturation can be obtained from fractional flow curves as shown in Fig. 1. The extrapolated tangent intercepting the line $f_{\mathrm{w}}=1$ represents the average water saturation $\bar{S}_{\mathrm{wT}}^{(1)}$. The slope of the tangent to $f_{w}{ }^{(1)}$ is expressed as:

$m=\frac{V \phi A}{q_{\mathrm{t}}}=\frac{V \phi}{u}$,

where $V$ is velocity of flood-front and $u$ is Darcy velocity.

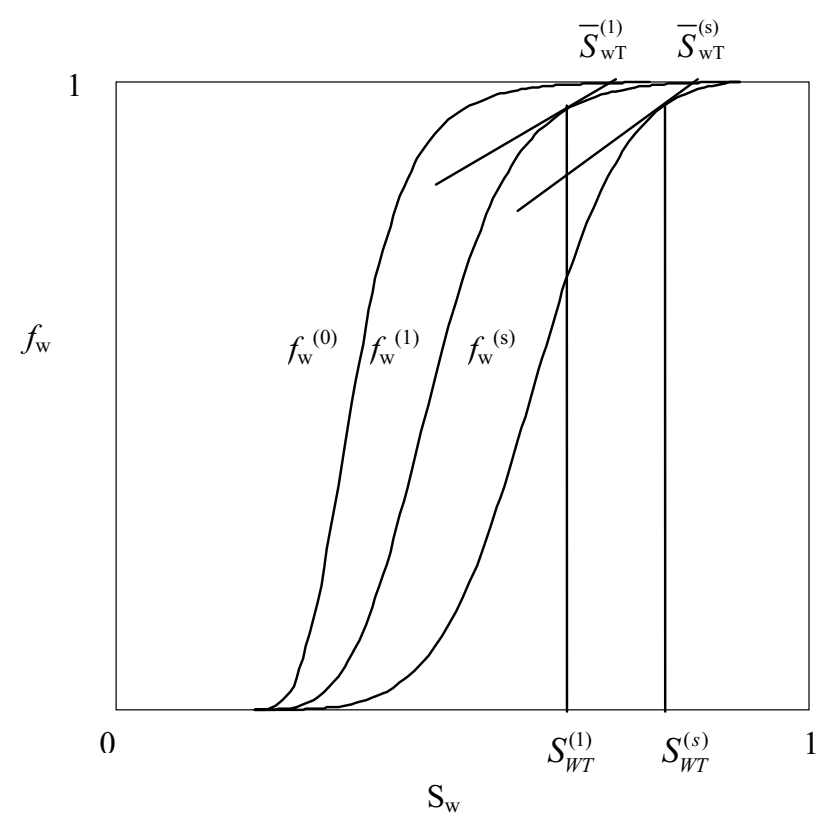

Fig. 1 Fractional flow curves 
In steam flooding process, steam and condensed water is continuously passing the front. $C_{1}$ is the concentration of the additive at $T_{1}$ and $C_{0}$ is the concentration at $T_{0}$; the velocity of injected solution $v$ can be obtained by application of the law of conservation of mass:

$v=\frac{u}{\phi} \frac{\bar{f}_{\mathrm{W}}{ }^{(1)}}{\bar{S}_{\mathrm{W}}{ }^{(1)}}$.

We assume it takes $\Delta t$ for the solution to arrive at floodfront, then:

$v \Delta t=V\left(t_{1}+\Delta t\right)$.

The following equation is obtained by combination of Eqs. (5), (6), and (7)

$\Delta t=\frac{t_{1}}{\frac{u}{V \phi} \frac{\bar{f}_{\mathrm{W}}{ }^{(1)}}{\bar{S}_{\mathrm{W}}{ }^{(1)}}-1}=\frac{t_{1}}{\frac{1}{m} \frac{\bar{f}_{\mathrm{W}}{ }^{(1)}}{{\overline{S_{\mathrm{W}}}}^{(1)}}-1}$.

Since $m<1$ and $\bar{f}_{\mathrm{w}}^{(1)}>\bar{S}_{\mathrm{W}}^{(1)}, \Delta t>0$ is proven, which means that the solution can reach flood-front and is saturated at either ahead of the front or behind it due to the temperature drop across the area.

Here residual resistance factor (RRF) is used to present the permeability reduction after hydrophilic additive is involved in the flooding process. The more RRF is, the more permeability is reduced

$\operatorname{RRF}\left(S_{\mathrm{A}}\right)=\frac{K_{\mathrm{rW}}\left(S_{\mathrm{W}}\right)}{K_{\mathrm{rW}}^{*}\left(S_{\mathrm{W}}, S_{\mathrm{A}}\right)} \geq 1$.

After additive is introduced to the displacement process, mobility ratio and oil recovery can be expressed as:

$M^{\mathrm{s}}=\frac{K_{\mathrm{rWT}}{ }^{(1)}}{R R F\left(S_{\mathrm{A}}\right) K_{\mathrm{rWT}}^{(0)}} \frac{\mu_{\mathrm{WT}}{ }^{(0)}}{\mu_{\mathrm{WT}}{ }^{(1)}}=\frac{M}{\operatorname{RRF}\left(S_{\mathrm{A}}\right)}$

$E_{\mathrm{R}}^{(s)}=\frac{\bar{S}_{\mathrm{WT}}{ }^{(s)}-S_{\mathrm{Wi}}}{1-S_{\mathrm{Wi}}}$,

where $M$ and $E_{\mathrm{R}}$ denote mobility ratio (water/oil) and oil recovery, respectively. Superscripts $\{s\}$ refer to the parameters after additive is introduced.
Since $S_{\mathrm{WT}}{ }^{(s)}>S_{\mathrm{WT}}{ }^{(l)}, E_{\mathrm{R}}{ }^{(s)}>E_{\mathrm{R}}{ }^{(l)}$ is proven. As is wellknown, the displacement front is stable when mobility ratio (invading/displaced) is reduced. From Eqs. (10) and (11), it is concluded that displacement process becomes more stable and oil recovery is enhanced by applying hydrophilic additive.

\section{Experimental}

\section{Additive screening and evaluation}

According to above-mentioned theory, the ability of the additive for mobility control is associated with solubility sensitive to temperature. The additive shall be highly soluble in water or steam at high temperature while hardly dissolved at low temperatures. This particular property will enable large amount of additives to be transferred to transition zone during steam flooding and precipitate by a temperature drop at the displacement front. The additive shall also remain stable under reservoir conditions and inert to crude oil. Flow path of condensed water in porous rock is occupied by the precipitated additive, resulting in the temporary reduction of relative water permeability. When steam is continuously injected and displacement front propagates, the precipitated additives are dissolved again in the subsequent condensed water or steam and conveyed further until another pressure drop at the mobile displacement front. This process repeats so that mobility of condensed water is controlled.

After reviewing chemicals handbook, MA presents perfect chemical and physical properties as discribed above for mobility control. MA is an organic compound, a trimer of cyanamide with a 1,3,5-triazine skeleton. The chemical and physical properties of MA are listed in Table 1.

MA has very limited solubility in cold water, but high aqueous solubility at high temperature. It is not soluble in crude oil. Experiment was conducted to meaure the aqueous solubility of MA under various temperatures. To measure aqueous solubility of MA at high temperature (above $100{ }^{\circ} \mathrm{C}$ ), a piston container with a certain volume of distilled water and excessive MA was placed in a thermostatic oven (maximum $350{ }^{\circ} \mathrm{C}$ ) at predetermined temperature for $24 \mathrm{~h}$. The pressure was also maintained at piston container to acertain water to be aqueous at the temperature. The saturated

Table 1 The chemical and physical properties of MA

Chemical formula Vapor pressure $\left(\mathrm{Pa}, 20^{\circ} \mathrm{C}\right) \quad$ Density $\left(\mathrm{g} / \mathrm{cm}^{3}\right) \quad$ Melting point $\left({ }^{\circ} \mathrm{C}\right) \quad$ Aqueous solubility $(\mathrm{g} / \mathrm{L})$ Autoignition temperature $\left({ }^{\circ} \mathrm{C}\right)$ $20{ }^{\circ} \mathrm{C} \quad 100{ }^{\circ} \mathrm{C}$

$\begin{array}{lllllll}\mathrm{C}_{3} \mathrm{H}_{6} \mathrm{~N}_{6} & 4.7 \times 10^{-8} & 1.574 & 354 & 3.2 & 5 & >500\end{array}$


solution was then displaced into a weighing bottle to measure MA mass after water vaporization and aqueous solubility was calculated. The result is presented in Fig. 2. As is shown, aqueous solubility is increased with temperature elevation, reaching $105.62 \mathrm{~g} / 100 \mathrm{~cm}^{3}$ at $250{ }^{\circ} \mathrm{C}$. In a steam flooding researvoir, large amount of MA can be carried by hot water or steam at high temperature and precipitate when temperature drops across the displacement front.

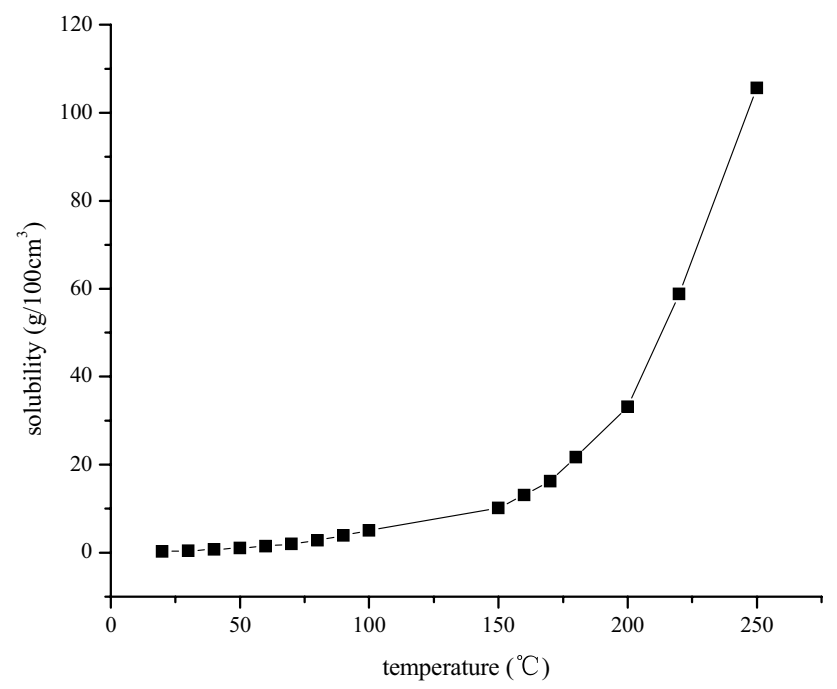

Fig. 2 Solubility of MA at various temperatures
It is of importance to maintain water-wet surface during thermal recovery process. Wettability of two pieces of natrual cores obtained from Block Qi40 of Liaohe Oilfield was evaluated by soaking in distilled water and saturated MA solution individually for 15 days at different temperatures then measuring contact angle using KRUSS device. The piece of core was polished before being soaked. A liquid drop was placed on the surface after soaking, then the photo of the liquid drop was taken for measuring contact angle. The contact angles results are shown in Fig. 3. The curves of contact angles are going down with increasing temperature. When temperature is elevated, resin and asphaltene adsorbed on the rock surface are gradually desorbed. This desorption process leads to an increase in water wettability. At relatively low temperature only small amount of MA was dissolved so that the wetability was not impacted too much. With more MA dissolved at high temperature, contact angle was decreased compared with that of core being soaked in distilled water, e.g., the contact angle was $8.8^{\circ}$ soaked in $200{ }^{\circ} \mathrm{C}$ MA while $12.4^{\circ}$ in distilled water. The core tends to be more water wet upon adding MA into water.

\section{MA precipitation in porous media}

Based on Eq. 10, water residual resistance factor $\left(\mathrm{RRF}_{\mathrm{w}}\right)$ can be used to approximately represent the mobility ratio of water/oil, namely demonstrate the ability of MA to plug off porous media. The basic elements in the experiment include

Fig. 3 Contact angles after cores being soaked for 15 days
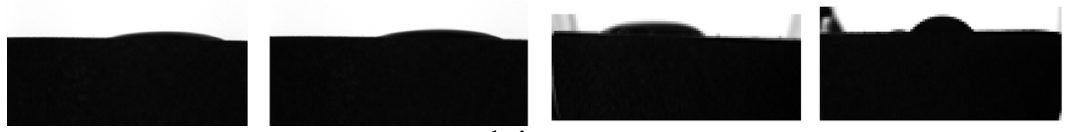

soak in water
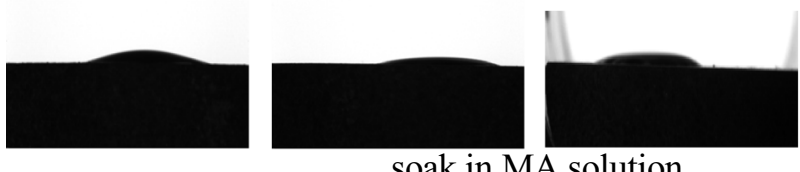

soak in MA solution

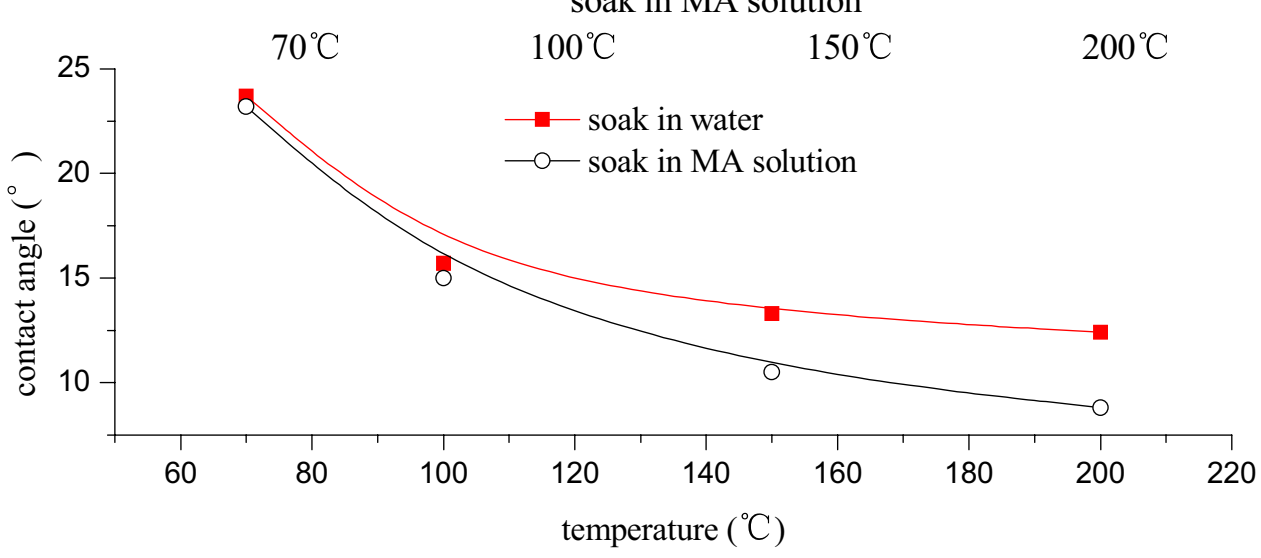


natural cores, formation water and MA. The natural cores were obtained from Block Qi40 of Liaohe Oilfield in China and the formation water was prepared with a mixture of $\mathrm{NaCl}(5 \mathrm{wt} \%)$ and $\mathrm{CaCl}_{2}$ (2 wt\%). MA was analytically pure, which was purchased from Shanghai Chemical Agent Plant.

All experiments were conducted using a modified steam flooding experimental system as shown in Fig. 4. The system is composed of injection pumps, thermostatic oven, core holder, pressure transmitter, back pressure system, confining pressure pump, vacuum systemp, metering system, and so on. The back pressure system can provide 0.2-50 MPa back pressure. The thermostatic oven can privide a maximum of $350{ }^{\circ} \mathrm{C}$ temperature and be cooled down by air ventilation for a quick temperature drop. A separator is included in the metering system to allow accruate measurement and all data will be recorded in the PC.

The labrotory procedures are as follows:

1. Measure the cores under dry condition, vacuum for $5 \mathrm{~h}$ then saturate with formation water, measure weight and calculate pore volume;

2. Exert confining pressure on cores to maintain $2 \mathrm{MPa}$ differential over outlet pressure;

3. Displace with formation water using constant-flow pump until stable parameters are obtained (0.1 MPa pump pressure and $1 \mathrm{ml} / \mathrm{min}$ ), five sets of data to be recorded to calculate water permeability;

4. Switch on thermostatic oven to maintain programmed temperatures for $5 \mathrm{~h}$ under confining pressure. Displace with saturated MA solution at programmed temperature then cool down to atmosphere temperature for $24 \mathrm{~h}$, calculate water permeability and $\mathrm{RRF}_{\mathrm{w}}$.
During experiments the range of temperature was from 150 to $240{ }^{\circ} \mathrm{C}$ and injected pore volumes (PV) of MA ranged from 0.5 to 2.0 PV. The results are shown in Fig. 5.

As shown in Fig. 5, $R F_{w}$ increased in response to the temperature rise and injected PV during MA injection. The solubility of MA in water increased with temperature elevation and vice versa, resulting in more MA being carried by water to precipitate at displacement front. The more temperature dropped, the more MA precipitated. It is obvious that temperature is one of the key influential factors in the process. The injected PV is also a very important factor. Higher volume of solution entrains more MA to precipitate for sealing off the highly permeable zones.

In general, it is always necessary to estimate the damage to reservoir when injecting additives. In the experiment,

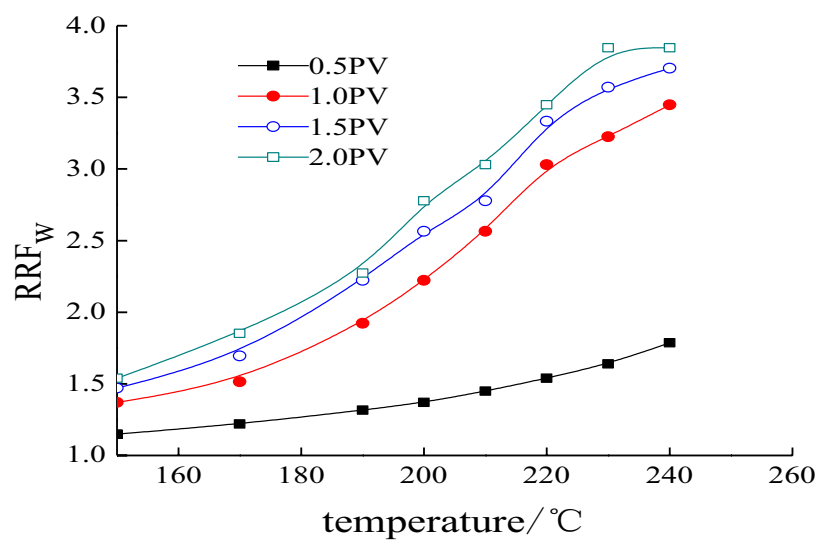

Fig. 5 The relationship between temperature and $\mathrm{RRF}_{\mathrm{w}}$ at various PVs

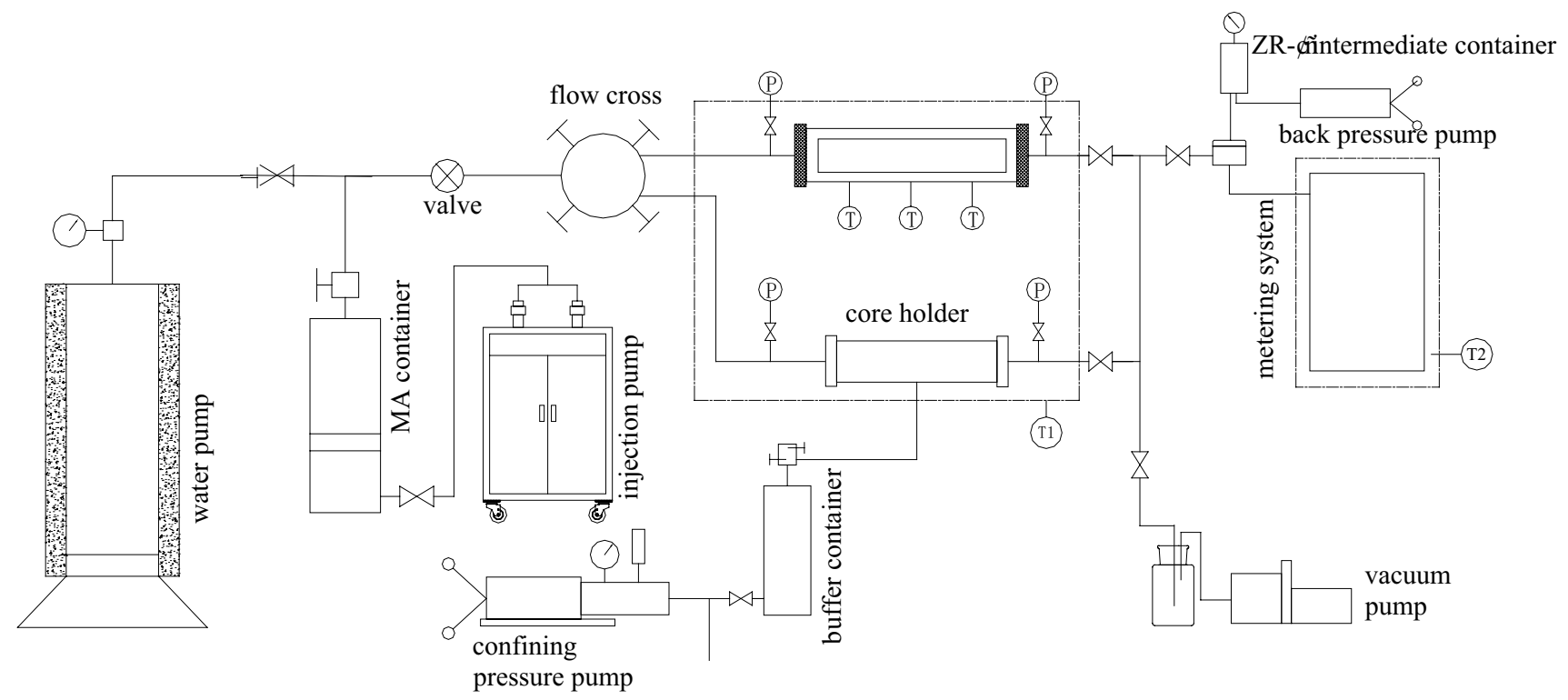

Fig. 4 A full view of the experimental system 
two cores with approximately same properties (permeability 0.581 and 0.526 Darcy, respectively) were filled with saturated solution of MA at $170{ }^{\circ} \mathrm{C}$. Then, the permeability was measured after temperature drop. Core\#1 was heated to $100{ }^{\circ} \mathrm{C}$ and displaced by 1 and $2 \mathrm{PV}$ of $100{ }^{\circ} \mathrm{C}$ hot water, respectively. Then the temperature was elevated to $150{ }^{\circ} \mathrm{C}$ and 1 and $2 \mathrm{PV}$ of $150{ }^{\circ} \mathrm{C}$ hot water was displaced. The experimental procedures were repeated on Core\#2 at the temperature ranging from 190 to $240{ }^{\circ} \mathrm{C}$. The effect of temperature on $\mathrm{RRF}_{\mathrm{w}}$ is shown in Fig. 6.

Figure 6 shows that $R_{R F}$ decreased with temperature rise and increased injected PV. The higher the temperature was, the closer the $\mathrm{RRF}_{\mathrm{w}}$ reached 1 . Hot water was more likely to dissolve the precipitated MA at high temperature, which led to the recovery of reduced permeability caused by MA precipitation. Injected PV behaved the same way as temperature. All results demonstrated that MA injection temporarily reduced relative water permeability with no damage to reservoir and the reduction of relative water permeability was recoverable under specific conditions.

In addition, the $\mathrm{RRF}_{\mathrm{o}}$ was also investigated to evaluate the impact of MA injection on relative oil permeability. In the experiment, four cores were initially saturated with MA solution at $240{ }^{\circ} \mathrm{C}$, then dropped in the controlled manner to $220,200,180$, and $160{ }^{\circ} \mathrm{C}$, respectively. The result is

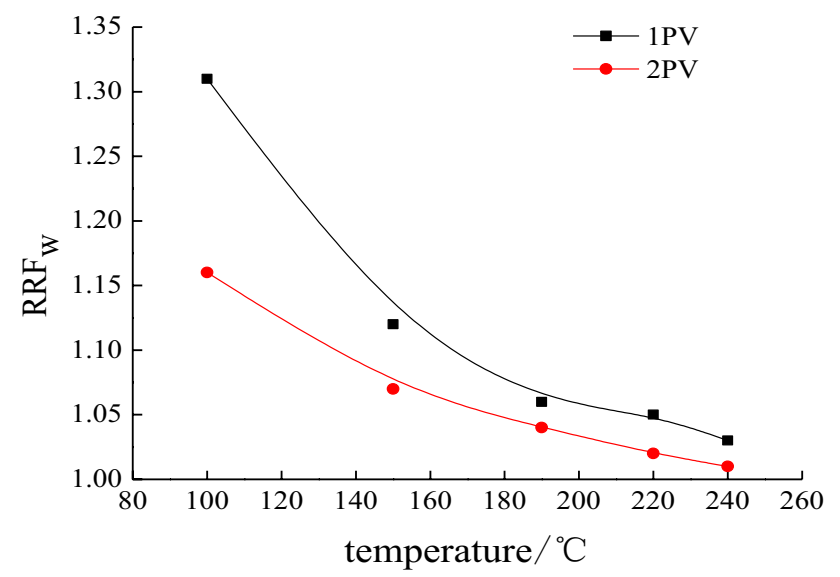

Fig. 6 Relationship between temperature and $\mathrm{RRF}_{\mathrm{w}}$ with different PVs shown in Table 2. As is shown, there was only slight reduction in relative oil permeability pre and post MA injection and $R_{R F}$ was very close to 1 . It is wellknow that introduction of heat to the reservoir rock will change the physical properties of the reservoir during thermal process. However, only neglectable change was observed in terms of relative oil permeability, which means no distirbulance was caused to oil flow by introducing MA solution into the reservoir. MA exibits the ability to control water/oil mobility ratio by increasing $R_{R F}$ while exerting neglectable impact on $\mathrm{RRF}_{\mathrm{o}}$, thus oil recovery is enhanced.

\section{Oil displacement experiment}

The $2.5 \mathrm{~mm} \times 10 \mathrm{~cm}$ artificial core was made of quartz, potassic feldspar, plagioclase, kaoline, montmorillonite, and chlorite in accordance with the rock constituents of Block Qi40 of Liaohe Oilfield, with porosity range from 24.1 to $26.6 \%$, and the permeability range from 1.51 to 1.57 Darcy. The heavy crude oil was obtained from Block Qi40. The relationship between oil viscosity and temperature is illustrated in Fig. 7. The formation water was prepared with a mixture of $\mathrm{NaCl}(5 \mathrm{wt} \%)$ and $\mathrm{CaCl}_{2}(2 \mathrm{wt} \%)$.

At the displacement front during steamflood, steam conveys the heat to formation fluids and condenses as hot water. Therefore, only hot waterflood was studied in this experiment. The temperature of hot water zones in a steamflood project of Block Qi40 ranged from 60 to $200{ }^{\circ} \mathrm{C}$. The experimental temperature of hot water was determined to be $60,100,160$ and $200{ }^{\circ} \mathrm{C}$, respectively. The oil displacemet experimental procedures as follows:

1. Establish initial oil/water conditions in the core.

2. Inject hot water or MA solution at required temperature and pressure, and maintain back pressure $0.5-1 \mathrm{MPa}$ over the saturated vapor pressure at the experimental temperatures.

3. When water cut is more than $98 \%$ and pressure differential across core is stable, the experiment is deemed to come to an end.

The water flooding efficiency by pure hot water is shown in Fig. 8. After the injection of saturated solution of MA at
Table $2 \mathrm{RRF}_{\mathrm{o}}$ comparison pre and post MA injection with various temperature drops

\begin{tabular}{lllllll}
\hline Core & Porosity $(\%)$ & $\begin{array}{l}\text { Permeability } \\
(\mathrm{D})\end{array}$ & $\begin{array}{l}\text { Temperature } \\
\left({ }^{\circ} \mathrm{C}\right)\end{array}$ & $\begin{array}{l}\text { Relative oil } \\
\text { Permeability } \\
\text { pre MA }\end{array}$ & $\begin{array}{l}\text { Relative oil } \\
\text { Permeability } \\
\text { post MA }\end{array}$ & $\mathrm{RRF}_{\mathrm{o}}$ \\
\hline 3 & 25.3 & 1.54 & 220 & 0.859 & 0.851 & 1.009401 \\
4 & 26.4 & 1.50 & 200 & 0.802 & 0.798 & 1.005013 \\
5 & 24.1 & 1.56 & 180 & 0.773 & 0.762 & 1.014436 \\
6 & 26.4 & 1.53 & 160 & 0.915 & 0.901 & 1.015538 \\
\hline
\end{tabular}




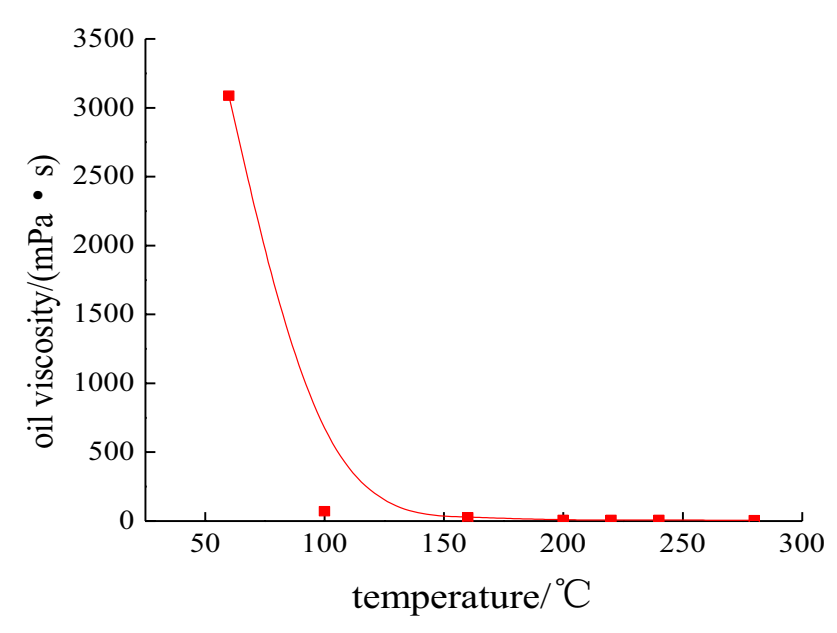

Fig. 7 Relationship curve of viscosity-temperature of crude oil from Block Qi40

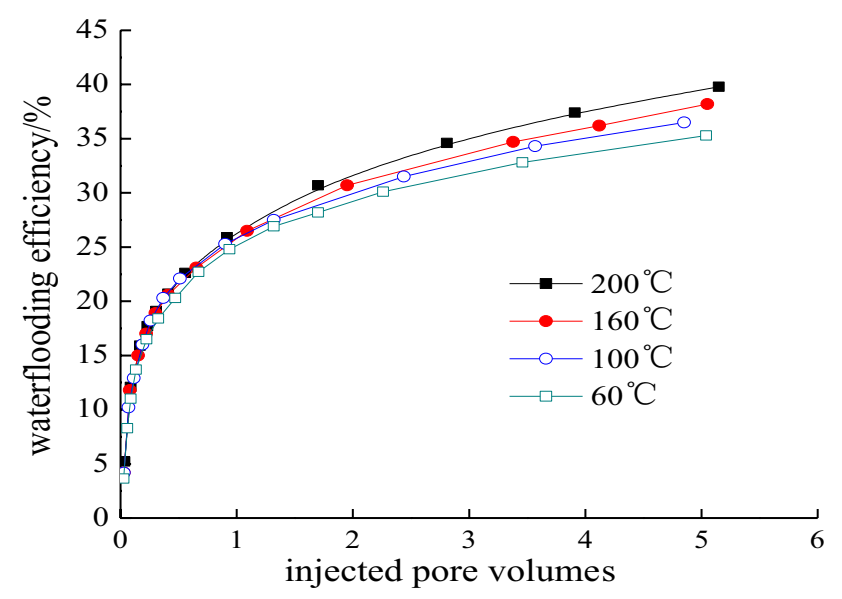

Fig. 8 Water flooding efficiency curve of the oil displacement experiments

$200{ }^{\circ} \mathrm{C}$, the temperature was dropped to $160{ }^{\circ} \mathrm{C}$ in a controlled manner. The core was then flooded by saturated solution of MA at the temperature of $160{ }^{\circ} \mathrm{C}$. Then the experiment was repeated with the temperature drop from 200 to $60{ }^{\circ} \mathrm{C}$. The results are demonstrated in Figs. 9 and 10.

Figure 8 shows that oil recovery was enhanced in response to the increase of injected water temperature. In hot water zones of a steamflood project, different oil recoveries were obtained when the injected water temperature varied from 60 to $200{ }^{\circ} \mathrm{C}$. The oil recovery by $200{ }^{\circ} \mathrm{C}$ hot water increased by $4.5 \%$ in comparison with the oil recovery by $60{ }^{\circ} \mathrm{C}$ hot water. Only small incremental oil recovery was obtained by elevating water temperature.

When the saturated solution of MA was used instead of hot water at the temperature of $200{ }^{\circ} \mathrm{C}$, as shown in Figs. 9 and 10 , the oil recovery by MA injection was not changing obviously at the beginning. Dissolved in hot water, MA

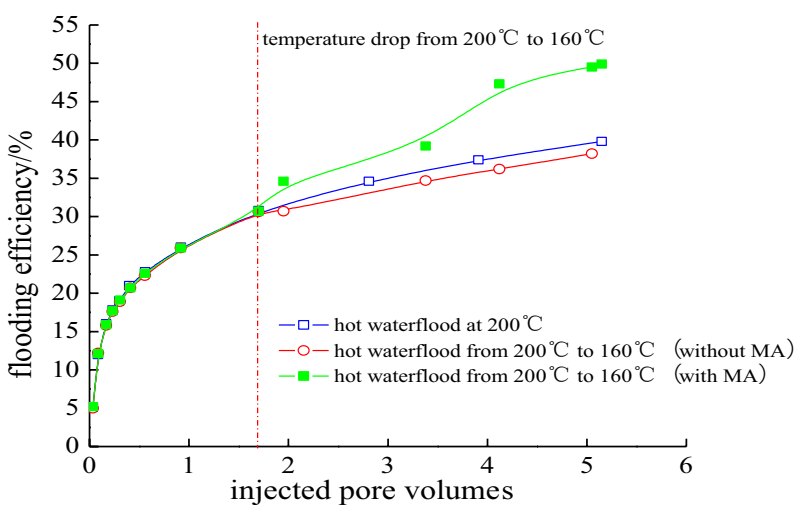

Fig. 9 Flooding efficiency comparison with temperature drop from 200 to $160{ }^{\circ} \mathrm{C}\left(200{ }^{\circ} \mathrm{C}\right.$ pure waterflood as reference $)$

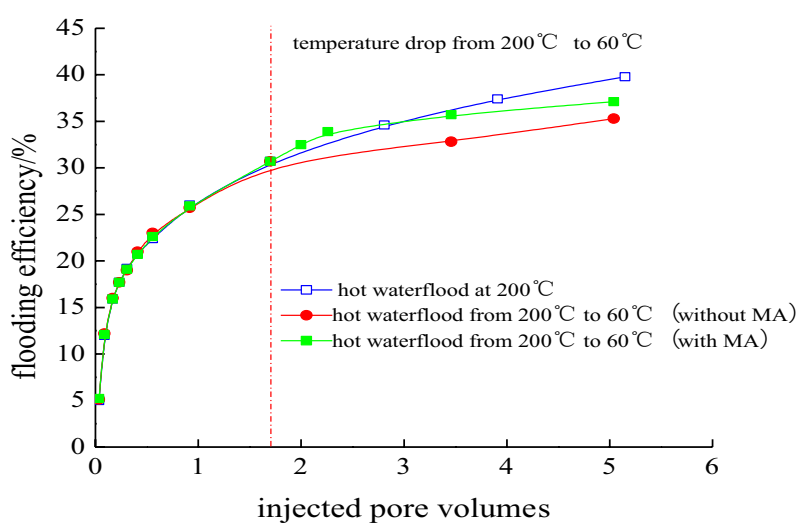

Fig. 10 Flooding efficiency comparison with temperature drop from 200 to $160{ }^{\circ} \mathrm{C}\left(200{ }^{\circ} \mathrm{C}\right.$ pure waterflood as reference $)$

did not function effectively when there was no temperature change. However, when the temperature dropped from 200 to $160{ }^{\circ} \mathrm{C}$ to simulate the heat loss at displacement front, the oil recovery was increased by $11.7 \%$ in comparison with pure water flooding under the same thermal condition and by $10.1 \%$ compared with $200{ }^{\circ} \mathrm{C}$ water flooding without temperature change. When the temperature dropped from 200 to $60{ }^{\circ} \mathrm{C}$, the oil recovery was about $37.1 \%$, which fell into the interval between $200{ }^{\circ} \mathrm{C}$ hot waterflood $(39.8 \%)$ and $60{ }^{\circ} \mathrm{C}$ hot waterflood (35.3\%).

The major reason why MA injection could enhance oil recovery during thermal process was that the precipitation of MA due to heat losses controlled mobility of condensed water by reducing relative water permeability and leaving oil permeability almost unaffected. The injected water was diverted into low permeability zones because its flow resistance in highly permeable zones increased. As a result, oil recovery was enhanced when swept volume was increased.

However, oil viscosity would also increase in the process of temperature drop since it is temperature sensitive. This 
would lead to the undesirable increase of water/oil mobility. When temperature dropped from 200 to $160{ }^{\circ} \mathrm{C}$, the limited increase of oil viscosity exerted very little unfavorable effects on water/oil mobility and the reduction of relative water permeability caused by MA precipitation was the dominant factor in this process. So the oil recovery is still greatly enhanced. When big temperature drop was encountered, e.g., from 200 to $60{ }^{\circ} \mathrm{C}$, oil viscosity increased to a relatively large extent, exerting unfavorable effects on water/ oil mobility. It explains in Fig. 10 that MA flooding efficiency is only $1.8 \%$ higher than hot waterflooding efficiency when temperature dropped from 200 to $60^{\circ} \mathrm{C}$. If huge heat losses occurred in a reservoir resulting in big temperature drop, MA would not behave as good as expected. Under such circumstances more MA precipitation could not compensate the undesired effects caused by oil viscosity increase due to big temperature drop.

\section{Conclusion}

A method of melamine-based mobility control method of condensed water during steam flooding process was introduced with the conclusions as follows:

1. Theoretical analysis has been made verifying that addition of MA can enhance oil recovery and RRFw can approximately represent mobility ratio.

2. Aqueous solubility of MA is increased with temperature elevation, reaching $105.62 \mathrm{~g} / 100 \mathrm{~cm}^{3}$ at $250{ }^{\circ} \mathrm{C}$ while $1.49 \mathrm{~g} / 100 \mathrm{~cm}^{3}$ at $60{ }^{\circ} \mathrm{C}$. This property allows MA to be dissolved at high temperature and precipitate at low temperature. Water wettability was also enhanced by addition of MA.

3. Water residual resistance factor increased in response to the temperature elevation and increased pore volume during MA injection. Water residual resistance factor reached close to 1 after subsequent hot water flood, which indicated that the reduced water permeability by MA precipitatation could be restored.

4. The oil recovery by saturated MA injection was increasd by $11.7 \%$ when temperature dropped from 200 to $160{ }^{\circ} \mathrm{C}$, in comparison with pure water flooding under the same condition. When temperature dropped from 200 to $60^{\circ} \mathrm{C}$, MA did not behave better in spite of more precipitation because oil viscosity was increased.

5. It has been verified that addition of MA can control mobility of condensed water during steam flooding process thus to enhance oil recovery.
Acknowledgements The authors thank Provincial Science Youth Innovation Fund (UNPYSCT-2017034), PetroChina Innovation Fund (Grant Number 2018D-5007-0212), and the National Science and Technology Major Project (Grant Number 2016ZX05002006) for financial support to this research.

\section{Compliance with ethical standards}

Conflict of interest The authors confirm that this article content has no conflict of interest.

Open Access This article is distributed under the terms of the Creative Commons Attribution 4.0 International License (http://creativeco mmons.org/licenses/by/4.0/), which permits unrestricted use, distribution, and reproduction in any medium, provided you give appropriate credit to the original author(s) and the source, provide a link to the Creative Commons license, and indicate if changes were made.

\section{References}

Buckley SE, Leverett MC (1942) Mechanism of fluid displacement in sands. Trans AIME 146:107-116. https://doi.org/10.2118/94210 7-G

Cai YC, Liu YJ, Fang X, Fan J, Yang J, Peng ZY, Li YY (2013) A Study on influence factor of steam flooding development effect in heavy oil reservoir. Appl Mech Mater 316:872-877. https://doi. org/10.4028/www.scientific.net/AMM.316-317.872

Hu SB (2011) Development and laboratory evaluation on mobility control agents used in oil recovery by steam injection. Dissertation, Northeast Petroleum University

Li RF, Yan W, Liu SH, Hirasaki GJ, Miller C (2010) A foam mobility control for surfactant enhanced oil recovery. SPE J 15:934-948. https://doi.org/10.2118/113910-PA

Li DX, Ren SR, Zhang PF, Zhang L, Feng YF, Jing YB (2017) $\mathrm{CO}_{2}$-sensitive and self-enhanced foams for mobility control during $\mathrm{CO}_{2}$ injection for improved oil recovery and geo-storage. Chem Eng Res Des 120:113-120. https://doi.org/10.1016/j.cherd .2017.02.010

Nonnekes LE, Cox SJ, Rossen WR (2015) Effect of gas diffusion on mobility of foam for enhanced oil recovery. Transp Porous Media 106:669-689. https://doi.org/10.1007/s11242-014-0419-z

Qian S, Zhang N, Li ZM, Wang YH (2016) Nanoparticle-stabilized foam for mobility control in enhanced oil recovery. Energy Technol 4:1084-1096. https://doi.org/10.1002/ente.201600093

Saleh TA, Sari A, Tuzen M (2017) Effective adsorption of antimony(III) from aqueous solutions by polyamide-graphene composite as a novel adsorbent. Chem Eng J 307:230-238. https ://doi.org/10.1016/j.cej.2016.08.070

Stoll RD, Gudenau HW, Lupik MW (1993) Mobility control for steamflooding with high-temperature-resistant additives. SPE Reserv Eng 8:281-284. https://doi.org/10.2118/21019-PA

Publisher's Note Springer Nature remains neutral with regard to jurisdictional claims in published maps and institutional affiliations. 